\title{
Effects of Stem Constriction Using Steel Washer Rings on the Soluble Solids Content of Pepino (Solanum muricatum Ait.) Fruit
}

\author{
Ken Takahata* \\ Department of Agriculture, Tokyo University of Agriculture, Atsugi 234-0034, Japan
}

The objective of this study was to determine whether planting pepino (Solanum muricatum Ait.) cuttings (shoots have 5 or 6 true leaves and length is $5-6 \mathrm{~cm}$ ) through the hole (diameter is $4 \mathrm{~mm}$ ) of a steel washer (hereinafter referred to as the "washer ring treatment") would increase the soluble solids content of pepino fruit. Experiments were conducted twice: i.e. from spring to summer (Experiment 1) and from autumn to spring (Experiment 2). The washer ring treatment caused marked increases in stem diameter immediately above the washer compared to the control, but slightly suppressed stem elongation and leaf unfolding. The stem diameter above the washer at the end of culture was smaller in the treated plants compared to the control plants. The fresh weights of both above-ground and root tissues were also smaller in the treated plants compared with control plants. In contrast, no differences were observed between the treated and control plants in the number of flowers, the fruit set ratio, or the disorder fruits ratio. The marketable fruits harvested from treated plants were smaller compared to those from control plants by 28 to $47 \mathrm{~g}$ and 66 to $147 \mathrm{~g}$ in Experiments 1 and 2, respectively (i.e. reduction in yield); however, the fruits were denser and contained more soluble solids at 1.1 to $2.4^{\circ} \mathrm{Brix}$ and 1.1 to $2.9^{\circ} \mathrm{Brix}$, respectively. This study confirmed that the washer ring treatment is effective for increasing the soluble solids content of pepino fruit.

Key Words: impeded translocation of photosynthates, root growth, stem diameter.

\section{Introduction}

Pepino (Solanum muricatum Ait.) is a fruit vegetable in the Solanaceae family and is presumed to be native to the South American countries (Heiser, 1964; Sakata, 2011). Pepino was introduced into Japan in the early 1980 s as an edible fruit, and local cultivation began soon thereafter. The market demands fruit with a soluble solid content of at least $10^{\circ} \mathrm{Brix}$; but according to newspaper accounts (The Japan Agricultural News dated 3 April 1985), the soluble solids content of pepino produced in Japan was as low as 6 to $8^{\circ}$ Brix. Therefore, pepino was poorly received in the market, and cultivation in Japan gradually declined (Sakata, 2011). In contrast, cultivars with relatively high soluble solids content have been bred and produced outside Japan. Even these new cultivars sometimes have a low soluble solids content depending on the growing season and can

Received; July 11, 2016. Accepted; November 17, 2016. First Published Online in J-STAGE on January 7, 2017.

Part of this study was presented at the 2014 autumn meeting of the Japanese Society for Horticultural Science.

* Corresponding author (E-mail:k5takaha@nodai.ac.jp). require further improvements (Prohens and Nuez, 1999; Rodriguez-Burruezo et al., 2004; Ruiz et al., 1997). In the tomato, also a Solanaceous plant, salt or water stress treatments (Johkan et al., 2014; Johnstone et al., 2005; Mitchell et al., 1991; Mizrahi et al., 1988; Saito et al., 2009; Sakamoto et al., 1999) and restriction of root growth (Motoki et al., 1994; Sakurai and Oyamada, 1995) increased the soluble solids content of the fruit. Salt and water stress are likely to increase the soluble solids content by directly restricting water absorption from the root, thus lowering the shoot water content. Pluda et al. (1993) reported that the soluble solids concentration increased in the fruit of pepino plants subjected to salt stress. Coiling wire around the lower part of tomato plant stems (basal wire coiling) was effective in producing fruit with a high soluble solids content (Takahata and Miura, 2014). Presumably, the high soluble solids content in the tomato fruit resulted from impeded translocation of photosynthates to the roots, which suppressed root growth and water absorption by the roots, resulting in shoots with a low water content. Pepino is propagated mostly by herbaceous cuttings (Sakata, 2011). Thus, I hypothesized that planting cuttings through washer holes ("washer ring treatment"), 
thereby restricting the diameter of the stem and impeding translocation of photosynthates to the roots, would suppress root growth and water absorption by the roots, resulting in shoots with a low water content. Overall this may increase the soluble solids content of pepino fruit in a manner similar to basal wire coiling. In this study, I investigated whether it is possible to produce pepino fruit with a high soluble solids content using the washer ring treatment.

\section{Materials and Methods}

\section{Plant culture and washer ring treatment}

Pepino plants ('Gold No.1', a major cultivar of pepino for dessert in Japan) were cultured in a glasshouse (Atsugi, Japan. The ventilation and heating temperatures were set to $25^{\circ} \mathrm{C}$ and $14^{\circ} \mathrm{C}$ ) from 19 April to 23 September 2013 (Experiment 1) and from 4 August 2013 to 16 April 2014 (Experiment 2). From 20 plants (about $20 \mathrm{~cm}$ from the ground to the shoot apex) that had many developing axillary buds, lateral shoots (5$6 \mathrm{~cm}$ shoot length) that had 5 or 6 true leaves of uniform size were collected and used as cuttings. After removing the lower two leaves, each cutting was planted vertically to a depth of about $2 \mathrm{~cm}$ (equivalent to the distance from the lower edge of the cutting to between the first and second leaves) in a $7.5 \mathrm{~cm}$ diameter plastic pot filled with mixed soil. The mixed soil was a 1:1 mixture of Supermix A $\left(\mathrm{N}: \mathrm{P}_{2} \mathrm{O}_{5}: \mathrm{K}_{2} \mathrm{O}=180: 120\right.$ : $220 \mathrm{mg} \cdot \mathrm{L}^{-1}$, Sakata Seed Corp., Yokohama, Japan) and Nippi-Engei-Baido-1gou $\quad\left(\mathrm{N}_{2} \mathrm{P}_{2} \mathrm{O}_{5}: \mathrm{K}_{2} \mathrm{O}=200: 2500\right.$ : $200 \mathrm{mg} \cdot \mathrm{L}^{-1}$, Nihon Hiryo Co., Ltd., Tokyo, Japan). This mixed soil was used in all subsequent treatments and the control. In the treated group, the cuttings were planted through steel washers $(4 \mathrm{~mm}$ inner diameter, $25 \mathrm{~mm}$ outer diameter, $1 \mathrm{~mm}$ thickness) placed on the soil surface. The plants were repotted in $10.5 \mathrm{~cm}$ diameter plastic pots when 8 to 9 leaves had emerged (13 May in Experiment 1 and 24 August in Experiment 2). The day when the stem size reached the inner diameter of the washer (26 May in Experiment 1 and 28 September in Experiment 2) was defined as 0 day after treatment (DAT). On 0 DAT, each of the plants was transferred to a larger plastic pot $(40 \mathrm{~cm}$ top diameter, $34 \mathrm{~cm}$ bottom diameter, $30 \mathrm{~cm}$ height) filled with $27 \mathrm{~L}$ of mixed soil. In each section of the glasshouse, 6 repetitions each consisting of two pots (total of 24 pots) were positioned in two rows so that the distance between two adjacent pots was $60 \mathrm{~cm}$ and the distance between the rows was $80 \mathrm{~cm}$. Each row included the same number of washer ring-treated and non-treated pots. At both ends of the rows, an extra plant was placed at each end (4 plants in total). Growth of the plants was guided with strings hanging from the ceiling for individual stem training (not pinched). A solution of 4chlorophenoxyacetic acid (4-CPA; 0.003\%) was sprayed at anthesis of the third flower to enhance fruit setting. According to Sakata (2011), the number of fruit per truss is limited to 2 or less in commercial pepino cultivation. In the experiments, all but the largest fruit in each truss were removed (fruit thinning) when the diameter of the largest fruit reached about $2 \mathrm{~cm}$. In Experiment 1, flowering of the first inflorescence started before the plants had grown to a sufficient size; therefore, the first inflorescence was removed when the first flower bloomed. The transferred plants were watered every day. Once every 10 days from July 5 and November 18, or the day of fruit thinning of the first truss in Experiments 1 and 2, respectively, $1000 \mathrm{~mL}$ and $500 \mathrm{~mL}$, respectively, of a 500 -fold dilution of liquid fertilizer (Hyponex; $\mathrm{N}: \mathrm{P}_{2} \mathrm{O}_{5}: \mathrm{K}_{2} \mathrm{O}=6: 10: 5 \%$, Hyponex Japan Corp. Ltd., Osaka, Japan) was applied to each pot instead of watering.

\section{Adjustment of water quantity}

After the final repotting, soil moisture sensors (EC-20; Decagon Devices, Pullman, WA, USA) were inserted into the pots about $6 \mathrm{~cm}$ away from the plant stems of four treated and four control plants to a depth of around 15 to $20 \mathrm{~cm}$. The soil moisture values (nominal volumetric water content percentage) displayed on a handheld reader $\left(\mathrm{ECH}_{2} \mathrm{O}\right.$ Check; Decagon Devices) were recorded every day at 10 AM. After measurement, the amount of water equivalent to the difference between the mean of the group and 19\% (target moisture content of the soil after irrigation) was supplied. No additional water was supplied to either group.

In a preliminary experiment, a soil moisture sensor and a pF meter (DIK-8333; Daiki Rika Kogyo Co., Ltd., Saitama, Japan) were inserted into a pot that contained the mixed soil (the same as that used to plant the pepino plants) but no plants. The pot was watered only once, and no water was supplied thereafter. Measurements by the moisture probe and $\mathrm{pF}$ meter were recorded daily, and the relationship between moisture content $(\%)$ and $\mathrm{pF}$ values of the mixed soil was investigated (Fig. 1).

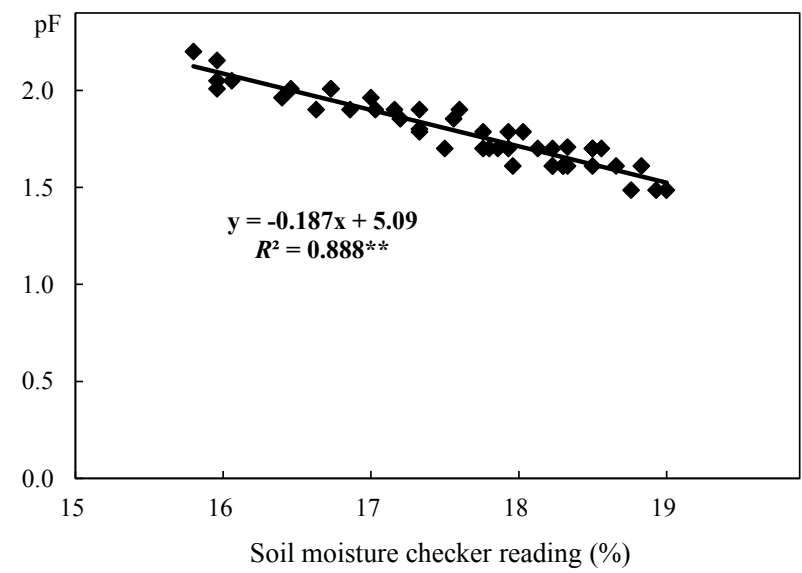

Fig. 1. Correlation between soil moisture content $(\%)$ and $\mathrm{pF}(\mathrm{n}=$ 46). $R^{2}$ : coefficient of determination. 


\section{Evaluation of plant growth}

Every ten days after the treatment, the stem diameter immediately above the washer (at the soil surface for the control plant), the stem length (from the soil surface to the shoot apex), and the number of nodes with unfolded leaves $(3 \mathrm{~cm} \leq)$ were recorded until termination of cultivation (120 and 200 DAT in Experiments 1 and 2 , respectively).

At the completion of the experiments, the stem diameter was measured immediately below the washer and 10,50 , and $70 \mathrm{~cm}$ above the washer. The fresh weights of the shoots (removing all inflorescences and trusses) and roots were also measured. The mixed soil was separated from the roots on a mesh screen using a stream of water from a hose, and the intact and broken roots from each plant were combined and blotted dry with paper towels before measuring the fresh weight. The shoots and the roots were dried in a greenhouse until the weight reached a constant value. The weights were then measured and expressed as air-dried weights. The T-R ratio was calculated from the air-dried weights of the shoots and the roots. The number of flowers and the fruit set ratio in the second to eight inflorescences and the first to seventh inflorescences were examined in Experiments 1 and 2, respectively. The fruit set ratio was calculated from the number of fruits from the first to fifth flowers at the time of fruit thinning ( 2 to 3 weeks after 4-CPA spraying).

\section{Evaluation of harvested fruit}

Fruit in the second to fifth trusses and the first to fourth trusses in Experiments 1 and 2, respectively, were harvested when their color was almost fully yellow. Marketable fruits, excluding those that had damage such as blossom-end rot or cracks, were examined. After removing the calyx, the weight and the diameter/ height ratio were measured. The fruit was then submerged in water; fruit volume was measured from its buoyancy, and the density $\left(\mathrm{g} \cdot \mathrm{cm}^{-3}\right)$ was calculated. The fruit was then divided longitudinally into four sections; two opposite fruit sections were wrapped in a double layer of gauze, and the fruit was squeezed to release the juice. The soluble solids content of the juice was measured using a digital refractometer (PR-101 $\alpha$; Atago Co., Ltd., Tokyo, Japan).

\section{Data analysis and statistics}

A total of six repetitions each consisting of two pots per replicate were examined. Excel was used for statistical analyses. For Evaluation of plant growth during cultivation, and stem diameter, shoot and root weights at the end of the experiments, a $t$-test was conducted to investigate whether there were significant differences between the mean values. For the developmental properties of inflorescences, a two-way analysis of variance was conducted by combining the position of the inflorescence and the washer ring treatment. For fruit, a two- way analysis of variance was conducted by combining the position of the truss and the washer ring treatment. When no interaction was found, but the effects of truss position and the washer ring treatment were found significant, the mean values were compared by using Tukey's test.

\section{Results}

Moisture content of the mixed soil after the final repotting

On days when the moisture content of the mixed soil was lower than $19 \%$, the pots were irrigated once a day to return the soil moisture content to $19 \%$. After the stem diameter equaled the inner diameter of the washer ring, the moisture content of the mixed soil before irrigation was $17.1-17.7 \%$ and $17.5-18.1 \%$ in the control and treated plants, respectively. A significant negative relationship of $\mathrm{y}=-0.187 \mathrm{x}+5.09\left(R^{2}=0.888^{* *}\right)$ was found between the moisture content of the mixed soil after stopping irrigation and $\mathrm{pF}$ (Fig. 1). The $\mathrm{pF}$ values for the mixed soil with moisture contents of 19, 17.117.7 , and $17.5-18.1 \%$ calculated using this regression formula were $1.54,1.89-1.78$, and $1.82-1.71$, respectively.

\section{Plant growth}

In Experiment 1, stem diameters immediately above the washer (Fig. 2A-1) were significantly longer than the corresponding stem parts in the control plants from 40 DAT onwards. At the end of the experiment (120 $\mathrm{DAT}$ ), the stem diameters of the treated plants were $44 \%$ longer than the diameters of the control plants (Fig. 3). The stem lengths of the treated plants (Fig. 2B-1) were significantly shorter than the control plants from 100 DAT onwards. The node number of the topmost unfolded leaf (Fig. 2C-1) was significantly smaller for the treated plants compared to the controls from 70 DAT onwards. In Experiment 2, the stem diameters immediately above the washer in the treated plants (Fig. 2A-2) were significantly longer compared to the control from 50 DAT onwards, 10 days later than in Experiment 1. In Experiment 2, stem length (Fig. 2B-2) and the node number of the uppermost leaf (Fig. 2C-2) of the treated plants were significantly smaller than for the control plants from 190 DAT onwards and 160 DAT onwards, respectively.

Stem diameter above the washer, shoot weight, and root weight at the completion of the experiments

In Experiment 1, the diameter of the stem immediately below the washer (Table 1) was significantly longer $(13 \%)$ for the treated plants compared to a comparable position (at the soil surface) in the control. In contrast, the diameter of the stem above the washer was significantly shorter ( 7 to $8 \%$ ) for the treated plants compared to the control. Both the fresh and air-dry shoot and root weights in the treated plants were significantly smaller 

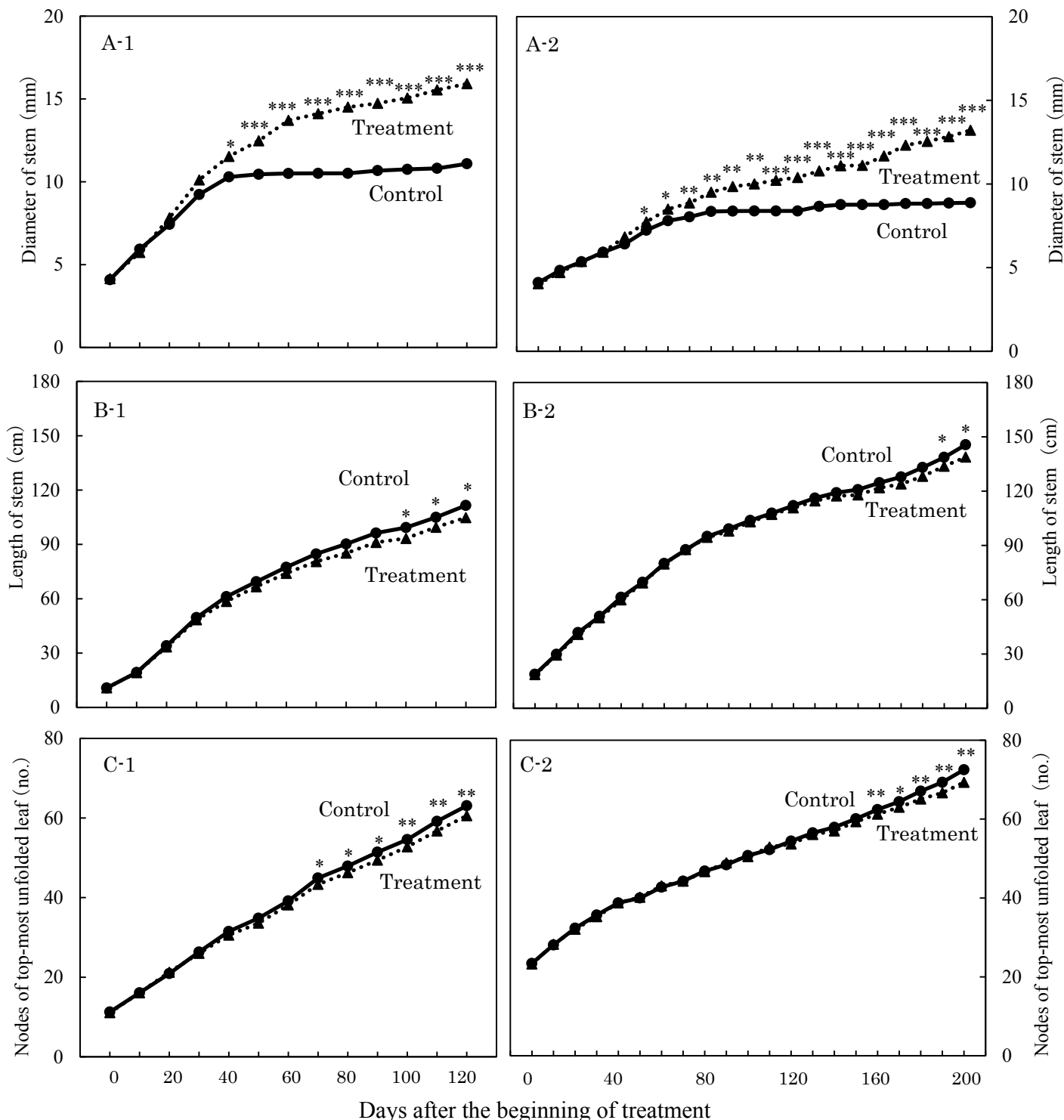

Fig. 2. Effects of the washer ring treatment on pepino stem thickening immediately above the washer ring (A), stem elongation (B), and leaf unfolding $(\mathrm{C})$ in Experiments $1(-1)$ and $2(-2)(\mathrm{n}=6)$. Diameter of the stem was measured at the soil surface for the control plant. *, **, and *** indicate significant differences by Student's $t$-test at $P<0.05,0.01$, and 0.001 , respectively.

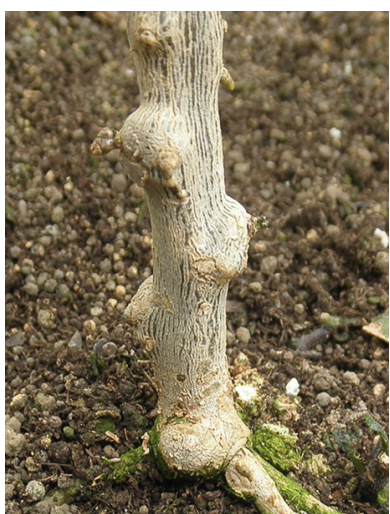

Control

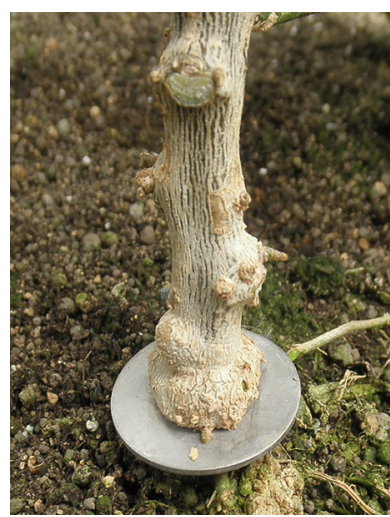

Treatment
Fig. 3. Stem morphology immediately above the washer ring compared with the control at the end of the Experiment 1 (120 days after treatment). by 14 to $19 \%$ and 23 to $26 \%$, respectively, than in the control. The T-R ratio was significantly larger by $16 \%$ for treated plants compared to the control. The results of Experiment 2 were similar to those in Experiment 1, except that there was no difference between the control and treated plants in the stem diameter at $10 \mathrm{~cm}$ above the washer and in the T- $\mathrm{R}$ ratio.

Number of flowers and the fruit set ratio of each inflorescence

In both Experiments 1 and 2, the number of flowers and the fruit set ratio of each inflorescence (Table 2) showed no significant difference in the main effect of treatment or interaction between the inflorescence positions and treatment. Only the main effect of inflorescence position was significant. When the inflorescence 
Table 1. Effects of washer ring treatment on pepino stem diameter, shoot weight, and root weight at the end of the experiments $(\mathrm{n}=6)$.

\begin{tabular}{|c|c|c|c|c|c|c|c|c|c|}
\hline \multirow{2}{*}{ Plot } & \multicolumn{4}{|c|}{ Stem diameters at the washer ring part ${ }^{\mathrm{z}}(\mathrm{mm})$} & \multicolumn{2}{|c|}{ Shoot $^{\mathrm{y}}$ weight $(\mathrm{g})$} & \multicolumn{2}{|c|}{ Root weight (g) } & \multirow{2}{*}{$\frac{\text { T-R }{ }^{\mathrm{x}} \text { raito }}{\text { Air-dry }}$} \\
\hline & Immediately below & Above $10 \mathrm{~cm}$ & Above $50 \mathrm{~cm}$ & Above $70 \mathrm{~cm}$ & Fresh & Air-dry & Fresh & Air-dry & \\
\hline \multicolumn{10}{|l|}{ Experiment 1} \\
\hline Control & 10.31 & 8.63 & 8.13 & 6.24 & 326 & 75.8 & 80.5 & 9.61 & 7.93 \\
\hline Treatment & 11.65 & 8.02 & 7.57 & 5.67 & 263 & 65.1 & 61.8 & 7.13 & 9.17 \\
\hline Significance $^{\mathrm{w}}$ & * & $* *$ & * & * & $* * *$ & ** & $* * *$ & $* * *$ & $* *$ \\
\hline \multicolumn{10}{|l|}{ Experiment 2} \\
\hline Control & 8.26 & 7.27 & 8.03 & 7.34 & 321 & 87.8 & 74.3 & 8.68 & 10.13 \\
\hline Treatment & 10.11 & 6.82 & 7.10 & 6.04 & 240 & 69.8 & 55.1 & 6.80 & 10.26 \\
\hline Significance & $* * *$ & NS & $* * *$ & $* * *$ & $* * *$ & $* *$ & $* * *$ & $* *$ & NS \\
\hline
\end{tabular}

z In the control, the distance from the soil surface.

y Stem and leaf (removing all inflorescences and trusses).

x Shoot weight/Root weight.

${ }^{w} \mathrm{NS}, * * *$, and $* * *$ indicate nonsignificant and significant differences by Student's $t$-test at $P<0.05,0.01$, and 0.001 , respectively.

positions were compared in Experiment 1, the number of flowers was largest in the third and fourth inflorescences. The fruit set ratio was significantly lower in the sixth to eighth inflorescences than that of the second to fifth inflorescences. In Experiment 2, inflorescences at higher positions had fewer flowers and had lower fruit set ratios.

\section{Evaluation of harvested fruit}

Marketable fruits were examined. In both Experiments 1 and 2, there was no significant difference in the disorder fruits ratio per plant between the control and treatment. In Experiment 1, the main effects of the ring treatment were significant for the number of days to harvest, weight, density, and soluble solids content (Table 3). No significant interaction was observed between the truss position and treatment. For all investigated parameters, the main effects of the truss position were also significant. In Experiment 2, the main effects of the ring treatment were significant except for the number of days to harvest; the main effects of the truss position were significant except for the diameter/height ratio. For all investigated parameters, there were no significant interactions between the truss position and the treatment.

The number of days from treatment to harvest was longer in the treated plants than in the control and was greater for trusses at higher positions in Experiment 1. In Experiment 2, the number of days from treatment to harvest was greater in trusses at higher positions, but there were no significant differences between the treated and control plants. The fruit weight by truss was lower in the treated plants by 34 to $16 \%$ compared to the control. In Experiment 1, the fruit weight was lower in trusses at higher positions in both the treated and control plants. In Experiment 2, there was a significant difference in fruit weight between truss positions. The weight values were small in the second and third trusses, but there was no specific trend between truss position and fruit weight. In Experiment 1, the fruit weight (i.e. yield) per truss in the control and treatment were $173 \mathrm{~g}$ and $136 \mathrm{~g}$, respectively. In Experiment 2, the fruit weight (i.e. yield) per truss in the control and treatment were $398 \mathrm{~g}$ and $290 \mathrm{~g}$, respectively. It follows that the fruit yield per truss of the treated plants was 73 to $79 \%$ of the control. Fruit density was higher in the treated group compared to the control in both Experiments 1 and 2. Fruit density was higher from the third to fifth truss than the second truss in Experiment 1. In Experiment 2, although there was a significant difference in fruit density in the first and third trusses, there was no significant difference otherwise. In Experiment 1, there were significant differences in the fruit diameter/height ratios among trusses, but the ring treatment had no effect. On the other hand, in Experiment 2 the ring treatment reduced the fruit diameter/height ratio significantly, but there were no significant differences among truss positions. The soluble solids content was higher in the treated group compared to the control by 1.6 and $1.8^{\circ}$ Brix on average in Experiments 1 and 2, respectively, irrespective of truss position. In both treated and control plants, the soluble solids content was higher in the trusses at higher positions.

\section{Discussion}

Takahata and Miura (2014) reported that a basal wire coiling technique could be used to produce tomato fruit that had a high soluble solids content, since the treatment markedly increased the stem diameter immediately above the coiled wire compared to the non-treated (control) plants. They reported that thickening of the stem was attributed to the wire coil inhibiting downward translocation of sieve tube sap that resulted in carbohydrate and auxin accumulation (Noel, 1970) immediately above the wire. Girdling tree trunks or branches also caused significant swelling immediately above the treatment as shown by Noel (1970), 
Table 2. Effects of the washer ring treatment on the number of pepino flowers per inflorescence and the fruit set ratio $(n=6)$.

\begin{tabular}{|c|c|c|c|c|c|}
\hline \multirow{2}{*}{ Inflorescence } & \multirow{2}{*}{ Plot } & \multicolumn{2}{|c|}{ Experiment 1} & \multicolumn{2}{|c|}{ Experiment 2} \\
\hline & & Number of flowers & Fruit set ratio $(\%)$ & Number of flowers & Fruit set ratio $(\%)$ \\
\hline \multicolumn{6}{|l|}{ First } \\
\hline & Control & - & - & 12.4 & 78.3 \\
\hline & Treatment & - & - & 11.8 & 78.3 \\
\hline & Mean & - & - & $12.1 \mathrm{ab}$ & $78.3 \mathrm{a}$ \\
\hline \multicolumn{6}{|l|}{ Second } \\
\hline & Control & 14.8 & 60.0 & 15.8 & 61.7 \\
\hline & Treatment & 16.3 & 70.0 & 14.3 & 71.7 \\
\hline & Mean & $15.5 \mathrm{~b}^{\mathrm{y}}$ & $65.0 \mathrm{ab}$ & $15.0 \mathrm{a}$ & $66.7 \mathrm{ab}$ \\
\hline \multicolumn{6}{|l|}{ Third } \\
\hline & Control & 25.3 & 86.7 & 12.7 & 45.0 \\
\hline & Treatment & 20.9 & 68.3 & 11.0 & 41.7 \\
\hline & Mean & $23.1 \mathrm{a}$ & $77.5 \mathrm{a}$ & $11.8 \mathrm{~b}$ & $43.3 \mathrm{bc}$ \\
\hline \multicolumn{6}{|l|}{ Fourth } \\
\hline & Control & 19.1 & 53.3 & 10.6 & 46.7 \\
\hline & Treatment & 20.3 & 61.7 & 11.4 & 51.7 \\
\hline & Mean & $19.7 \mathrm{a}$ & $57.5 \mathrm{~b}$ & $11.0 \mathrm{bc}$ & $49.2 \mathrm{abc}$ \\
\hline \multicolumn{6}{|l|}{ Fifth } \\
\hline & Control & 14.0 & 55.0 & 10.6 & 15.0 \\
\hline & Treatment & 16.3 & 46.7 & 11.5 & 15.0 \\
\hline & Mean & $15.1 \mathrm{~b}$ & $50.8 \mathrm{~b}$ & $11.0 \mathrm{bc}$ & $15.0 \mathrm{~d}$ \\
\hline \multicolumn{6}{|l|}{ Sixth } \\
\hline & Control & 13.3 & 3.3 & 9.2 & 31.7 \\
\hline & Treatment & 14.6 & 8.3 & 9.8 & 35.0 \\
\hline & Mean & $14.0 \mathrm{~b}$ & $5.8 \mathrm{c}$ & $9.5 \mathrm{bc}$ & $33.3 \mathrm{~cd}$ \\
\hline \multicolumn{6}{|l|}{ Seventh } \\
\hline & Control & 12.3 & 6.7 & 8.7 & 38.3 \\
\hline & Treatment & 13.3 & 6.7 & 8.9 & 41.7 \\
\hline & Mean & $12.8 \mathrm{~b}$ & $6.7 \mathrm{c}$ & $8.8 \mathrm{c}$ & $40.0 \mathrm{bcd}$ \\
\hline \multicolumn{6}{|l|}{ Eighth } \\
\hline & Control & 13.3 & 13.3 & - & - \\
\hline & Treatment & 14.3 & 3.3 & - & - \\
\hline & Mean & $13.8 \mathrm{~b}$ & $8.3 \mathrm{c}$ & - & - \\
\hline & Inflorescence & $* *^{\mathrm{x}}$ & $* *$ & $* *$ & $* *$ \\
\hline & Treatment & NS & NS & NS & NS \\
\hline & Interaction & NS & NS & NS & NS \\
\hline
\end{tabular}

${ }^{\mathrm{z}}$ Calculated with the first to fifth flowers of each inflorescence: fruit set ratio $(\%)=$ number of fruits $/ 5 \times 100$. For the fruit set ratio, an angular transformation was conducted.

${ }^{y}$ In comparisons between the mean values of the rows, different letters indicate a significant difference by Tukey's test at $P<0.05$.

${ }^{x} \mathrm{NS}$ and $* *$ indicate nonsignificant and significant differences by two-way analysis of variance at $P<0.01$ respectively.

Richardson (1975), Sitton (1949), and many others. Mason and Maskell (1928) and Greene (1937) reported that sugars accumulated in branches above the treatment. From the descriptions in these references, stem swelling immediately above the treatment in this experiment (Fig. 2A) is thought to have resulted from accumulation of carbohydrates and plant hormones immediately above the treatment due to impeded downward translocation of sieve tube sap, which, similar to girdling and coiling, activated the growth of wounded and healed tissue and cambial cell division more intensely than in non-treated plants. Moreover, impeded photosynthate translocation to parts below the treatment started by stem swelling immediately above the treatment, and presumably suppressed root growth (Table 1) leading to stem elongation (Fig. 2B) and leaf development (Fig. 2C) successively. This is the same result as for basal wire coiling (Takahata and Miura, 2014). As a result, it is thought that the stem above the processing part became thinner as shown in Table 1 .

Methods that have been reported to be effective in increasing the soluble solids content of tomato fruit include inducing salt stress (Johkan et al., 2014; Mizrahi et al., 1988; Saito et al., 2009; Sakamoto et al., 1999), 
Table 3. Effects of the washer ring treatment from treatment to harvest on fruit weight and density, diameter/height, and soluble solids content of pepino fruit $(n=6)$.

\begin{tabular}{|c|c|c|c|c|c|c|c|c|c|c|c|c|c|c|c|}
\hline \multirow{2}{*}{ Truss } & \multicolumn{3}{|c|}{$\begin{array}{l}\text { Time } \\
(\mathrm{d})^{\mathrm{z}}\end{array}$} & \multicolumn{3}{|c|}{$\begin{array}{l}\text { Weight } \\
\text { (g/fruit) }\end{array}$} & \multicolumn{3}{|c|}{$\begin{array}{l}\text { Density } \\
\left(\mathrm{g} \cdot \mathrm{cm}^{-3}\right)\end{array}$} & \multicolumn{3}{|c|}{$\begin{array}{c}\text { Shape } \\
\text { (diameter/height) }\end{array}$} & \multicolumn{3}{|c|}{$\begin{array}{l}\text { Soluble solids content } \\
\left.\text { ( }{ }^{\circ} \text { Brix }\right)\end{array}$} \\
\hline & Control & Treatment & Mean & Control & Treatment & Mean & Control & Treatment & Mean & Control & Treatment & Mean & Control & Treatment & Mean \\
\hline \multicolumn{16}{|l|}{ Experiment 1} \\
\hline Second & 82.8 & 82.6 & $82.7 c^{y}$ & 303 & 256 & $280 \mathrm{a}$ & 1.01 & 1.02 & $1.02 \mathrm{~b}$ & 1.24 & 1.21 & $1.23 \mathrm{~b}$ & 8.2 & 9.3 & $8.8 \mathrm{~b}$ \\
\hline Third & 89.9 & 91.8 & $90.8 \mathrm{~b}$ & 141 & 104 & $123 \mathrm{~b}$ & 1.10 & 1.18 & $1.14 \mathrm{a}$ & 1.23 & 1.20 & $1.21 \mathrm{~b}$ & 8.3 & 10.1 & $9.2 \mathrm{~b}$ \\
\hline Fourth & 94.8 & 97.2 & $96.0 \mathrm{a}$ & 122 & 94 & $108 \mathrm{~b}$ & 1.13 & 1.20 & $1.17 \mathrm{a}$ & 1.31 & 1.34 & $1.33 \mathrm{a}$ & 9.1 & 10.4 & $9.8 \mathrm{ab}$ \\
\hline Fifth & 95.3 & 98.3 & $96.8 \mathrm{a}$ & 124 & 88 & $106 \mathrm{~b}$ & 1.13 & 1.30 & $1.22 \mathrm{a}$ & 1.27 & 1.34 & $1.30 \mathrm{ab}$ & 9.4 & 11.8 & $10.6 \mathrm{a}$ \\
\hline Mean & $90.7 \mathrm{~B}^{\mathrm{x}}$ & $92.5 \mathrm{~A}$ & & $173 \mathrm{~A}$ & $136 \mathrm{~B}$ & & $1.10 \mathrm{~B}$ & $1.17 \mathrm{~A}$ & & 1.26 & 1.27 & & $8.8 \mathrm{~B}$ & $10.4 \mathrm{~A}$ & \\
\hline Treatment & & $* *^{\mathrm{w}}$ & & & $* *$ & & & $* *$ & & & NS & & & $* *$ & \\
\hline Truss & & $* *$ & & & $* *$ & & & $* *$ & & & $* *$ & & & $* *$ & \\
\hline Interaction & & NS & & & NS & & & NS & & & NS & & & NS & \\
\hline \multicolumn{16}{|l|}{ Experiment 2} \\
\hline First & 142 & 141 & $141 \mathrm{~d}$ & 458 & 368 & $413 \mathrm{a}$ & 1.00 & 1.04 & $1.02 \mathrm{~b}$ & 1.35 & 1.23 & 1.29 & 8.0 & 9.1 & $8.5 \mathrm{~b}$ \\
\hline Second & 165 & 165 & $165 \mathrm{c}$ & 330 & 264 & 297 b & 1.05 & 1.09 & $1.07 \mathrm{ab}$ & 1.29 & 1.25 & 1.27 & 10.0 & 11.6 & $10.8 \mathrm{a}$ \\
\hline Third & 181 & 179 & $180 \mathrm{~b}$ & 374 & 245 & $310 \mathrm{~b}$ & 1.04 & 1.13 & $1.09 \mathrm{a}$ & 1.33 & 1.21 & 1.27 & 10.6 & 12.5 & $11.6 \mathrm{a}$ \\
\hline Fourth & 191 & 191 & $191 \mathrm{a}$ & 428 & 281 & $355 \mathrm{ab}$ & 1.02 & 1.09 & $1.05 \mathrm{ab}$ & 1.29 & 1.25 & 1.27 & 10.5 & 13.4 & $11.9 \mathrm{a}$ \\
\hline Mean & 170 & 169 & & $398 \mathrm{~A}$ & $290 \mathrm{~B}$ & & $1.03 \mathrm{~B}$ & $1.09 \mathrm{~A}$ & & $1.31 \mathrm{~A}$ & $1.24 \mathrm{~B}$ & & $9.8 \mathrm{~B}$ & $11.6 \mathrm{~A}$ & \\
\hline Treatment & & NS & & & $* *$ & & & $* *$ & & & $* *$ & & & $* *$ & \\
\hline Truss & & $* *$ & & & $* *$ & & & $* *$ & & & NS & & & $* *$ & \\
\hline Interaction & & NS & & & NS & & & NS & & & NS & & & NS & \\
\hline
\end{tabular}

z Days from treatment to harvest.

y Different lower-case letters indicate significant differences in trusses by Tukey's multiple range test at $P<0.05$.

x Different capital letters indicate significant differences in treatment by Tukey's multiple range test at $P<0.05$.

${ }^{w} \mathrm{NS}$ and $* *$ indicate nonsignificant and significant differences by two-way analysis of variance at $P<0.01$, respectively.

limiting the amount of water (Johnstone et al., 2005; Mitchell et al., 1991), restricting the root zone (Motoki et al., 1994; Sakurai and Oyamada, 1995), and binding wire around the stem (Takahata and Miura, 2014). Of these methods, salt and water stresses restrict water absorbance by the roots. In contrast, root-zone restriction and wire coiling are thought to suppress root growth, causing an imbalance between water absorption and transpiration. This was the case in Experiment 1; suppression of root growth compared to the growth of the above-ground tissues may have caused water stress in the washer ring-treated plants. In Experiment 2, however, the T-R ratio (based on air-dry weight) showed no difference between the control and treated plants (Table 1). Thus, the effects of the washer ring treatment on the soluble solids content are difficult to explain entirely by the balance between the root and above-ground tissues. There have been several studies reporting increases in the soluble solids content of fruit by girdling the trunks of apple trees (Arakawa et al., 1997), girdling the main vine in grapes (Fujishima et al., 2005), girdling lateral vines in kiwi plants (Murakami, 2012), and strapping lateral bearing branches in persimmons (Hasegawa and Nakajima, 1991). Tomato treatments, such as salt stress, water stress, and restriction of the root growth sphere, all influence water levels in the root sphere and suppress water absorption by roots. Because washer ring treatment in this experiment markedly suppressed root growth (Table 1), it is thought to have reduced water absorption. Because stem and leaf growth were also suppressed (Fig. 2B, C), washer ring treatment is also thought to have reduced the amount of photosynthate production per plant. However, the decrease in moisture content conceivably surpassed the decrease in the amount of photosynthate production to increase the soluble solids content in fruit juice.

In this study, cultivation experiments were conducted twice in distinct seasons. In both experiments, the soluble solids content exceeded $10^{\circ}$ Brix in the treated group for all trusses except the first truss (Table 3). Also, the washer ring treatment reduced the fruit yield per truss by 21 to $27 \%$ and the fruit weight to $34 \%$ of the maximum (Table 3), but such a reduction is commonly observed in tomato fruit with a high soluble solids content (Saito et al., 2009; Sakamoto et al., 1999). However, the most important pepino fruit quality is a soluble solids content of $10^{\circ}$ Brix or more. No disorders, such as etiolation and wilt, were observed in treated plants up to completion of the experiment. Almost no reduction in the number of flowers, or a low fruit set ratio were observed (Table 2). These results show that pepino fruits of high soluble solids content may be grown using a comparatively simple technique.

Pluda et al. (1993) showed that pepino fruit with a 
high soluble solids content can be produced by imposing salt stress; however, salt stress in soil culture deteriorates the physical properties of the soil and in hydroponic culture requires special equipment. Soil culture under water stress conditions is also expected to have similar effects to salt stress, but requires a soil moisture sensor and a system for regulating the amount of irrigation. Hayata et al. (1998) cultivated cherry tomatoes by adjusting the soil moisture content $(\mathrm{pF})$ to 2.0 in the control, 1.5 in an excessively-watered treatment, 2.5 in a mildly water-stressed treatment, and 2.9 in a water-stressed treatment. In the water-stressed treatment, the total dry weight per plant and the weight per fruit were sharply lower compared to the excessively-watered treatment, and the soluble solids content was high. However, there were no big differences between the wet and control treatments in fruit weight or soluble solids content, but the total dry weight of the plant increased by $12 \%$ in the excessively-watered treatment. Therefore, soil moisture contents of pF1.5 to 2.0 are likely to be suitable for tomato cultivation. Favorable soil moisture contents for pepino cultivation have not yet been determined. Assuming that the $\mathrm{pF}$ values suitable for fruit growth and soluble solids content do not differ between the tomato and pepino, sufficient water was likely to have been supplied to the pepino plants in both the control and treated plants because $\mathrm{pF}$ fluctuated between 1.5 and 1.9 in this study (Fig. 1). The results of this study showed that the washer ring treatment was effective in increasing the soluble solids content of the fruit, even under well-watered conditions. I used a soil moisture sensor to maintain a uniform soil moisture content after irrigation in both the control and treated plants, but it was probably not necessary to adjust the soil moisture content using the sensor because the effect of washer ring treatment was evident even under well-watered conditions. The washer ring treatment is similar to rootzone restriction in that both methods suppress the growth of the root and reduce the moisture content of the plant, but the former is likely superior to the latter because it does not require the placement of sheets in the field. The washer ring treatment is simpler than conventional methods used for tomato cultivation to achieve high soluble solids content and is easy for small-scale farmers to implement. In this study, plants were grown in $27 \mathrm{~L}$ pots filled with mixed soil. The use of $27 \mathrm{~L}$ pots was unlikely to have restricted the root zone because the plants had not formed root balls even at the completion of the experiment, and the soluble solids content of all fruit in all trusses of the control group in Experiment 1 did not reach $10^{\circ}$ Brix (Table 3). The decrease in fruit weight in the treatment is thought to have resulted from the suppression of fruit enlargement due to decreased amounts of water absorption by roots and the increased density is judged to be an effect of increased concentrations of soluble solids in fruit juice. In Experiment 1, the number of days from the beginning of treatment to harvest did not differ between the fourth and fifth trusses in the treated and control plants, and the weight per fruit harvested from the upper trusses was small (Table 3). This result likely happened because the flowers in the upper inflorescences flowered and developed into fruit during summer days with high temperatures (above $25^{\circ} \mathrm{C}$ ). In conclusion, the washer ring treatment can increase the soluble solids content of pepino fruit as initially hypothesized. The practical application of washer ring treatment to pepino culture will require further investigation, e.g., to identify the optimum inner diameter and width of treatment in order to cultivate under conditions similar to those at production sites.

\section{Acknowledgements}

I am grateful to Prof. Nobuo Sugiyama for his helpful criticism of this manuscript. I sincerely thank Yoshie Isono, Miki Ohshita, Jun Arie, Hisashi Kuroiwa, and Takahiro Chugo for their cooperation in this study.

\section{Literature Cited}

Arakawa, O., K. Kanno, A. Kanetsuka and Y. Shiozaki. 1997. Effects of girdling and bark inversion on tree growth and fruit quality of apple. Acta Hortic. 451: 579-585.

Fujishima, F., M. Shiraishi, S. Shimomura and Y. Horie. 2005. Effects of girdling on berry quality of 'Pione' grapevine. Hort. Res. (Japan) 4: 313-318 (In Japanese with English abstract).

Greene, L. 1937. Ringing and fruit setting as related to nitrogen and carbohydrate content of grimes golden apples. J. Agric. Res. 54: 863-875.

Hasegawa, K. and Y. Nakajima. 1991. Effect of strapping lateral bearing branches with wires on flowering and fruit quality of persimmon (Diospyros kaki L.) cvs. Saijo and MaekawaJiro. J. Japan. Soc. Hort. Sci. 60: 291-299 (In Japanese with English abstract).

Hayata, Y., T. Tobe, S. Kondo and K. Inoue. 1998. The effects of water stress on the growth, sugar and nitrogen content of cherry tomato fruit. J. Japan. Soc. Hort. Sci. 67: 759-766 (In Japanese with English abstract).

Heiser, C. B. 1964. Origin and variability of the pepino (Solanum muricatum): A preliminary report. Baileya 12: 151-158.

Johkan, M., A. Nagatsuka, A. Yoshitomi, T. Nakagawa, T. Maruo, S. Tsukagoshi, M. Hohjo, N. Lu, A. Nakaminami, K. Tsuchiya and Y. Shinohara. 2014. Effect of moderate salinity stress on the sugar concentration and fruit yield in singletruss, high-density tomato production system. J. Japan. Soc. Hort. Sci. 83: 229-234.

Johnstone, P. R., T. K. Hartz, M. LeStrange, J. J. Nunez and E. M. Miyao. 2005. Managing fruit soluble solids with late-season deficit irrigation in drip-irrigated processing tomato production. HortScience 40: 1857-1861.

Mason, T. G. and E. J. Maskell. 1928. Studies on the transport of carbohydrates in the cotton plant. I. A study of diurnal variation in the carbohydrates of leaf, bark, and wood, and of the effects of ringing. Ann. Bot. 57: 189-253.

Mitchell, J. P., C. Shennan, S. R. Grattan and D. M. May. 1991. Tomato fruit yields and quality under water deficit and salinity. J. Amer. Soc. Hort. Sci. 116: 215-221. 
Mizrahi, Y., E. Taleisnik, V. Kagan-Zur, Y. Zohar, R. Offenbach, E. Matan and R. Golan. 1988. A saline irrigation regime for improving tomato fruit quality without reducing yield. J. Amer. Soc. Hort. Sci. 113: 202-205.

Motoki, S., Y. Yanokuchi, K. Okamoto and K. Ito. 1994. Effect of watering and applied fertilizer on fruit yield and fruit quality in a tomato culture using polyester sheets for restriction of rooting zone. 1994. Nagano Chushin Agr. Ex. Sta. 12: 31-45 (In Japanese with English abstract).

Murakami, S. 2012. Effect of girdling methods on fruit quality in 'Rainbow Red' kiwifruit (Actinidia chinensis). Hort. Res. (Japan) 11: 281-287 (In Japanese with English abstract).

Noel, A. R. A. 1970. The girdled tree. Bot. Rev. 36: 162-195.

Pluda, D., H. D. Rabinowitch and U. Kafkafi. 1993. Pepino dulce (Solanum muricatum Ait.) quality characteristics respond to nitrogen nutrition and salinity. J. Amer. Soc. Hort. Sci. 118: 86-91.

Prohens, J. and F. Nuez. 1999. Strategies for breeding a new greenhouse crop, the pepino (Solanum muricatum Ation). Can. J. Plant Sci. 79: 269-275.

Richardson, M. 1975. Translocation in plants. 2nd ed. Edward Arnold, London.

Rodriguez-Burruezo, A., J. Prohens and F. Nuez. 2004. 'Valencia': A new pepino (Solanum muricatum) cultivar with improved fruit quality. HortScience 39: 1500-1502.
Ruiz, J. J., J. Prohens and F. Nuez. 1997. 'Sweet Round' and 'Sweet Long': Two pepino cultivars for Mediterranean climates. HortScience 32: 751-752.

Saito, T., N. Fukuda, C. Matsukura and S. Nishimura. 2009. Effects of salinity on distribution of photosynthates and carbohydrate metabolism in tomato growth using nutrient film technique. J. Japan. Soc. Hort. Sci. 78: 90-96.

Sakamoto, Y., S. Watanabe, T. Nakashima and K. Okano. 1999. Effects of salinity at two ripening stages on the fruit quality of single-truss tomato grown in hydroponics. J. Hort. Sci. Biotech. 74: 690-693.

Sakata, Y. 2011. Pepino. p. 305-309. In: Nosangyosonbunkakyokai (ed.). Encyclopedia of growing vegetables 20. 2nd ed. (In Japanese). Nosangyosonbunkakyokai, Tokyo.

Sakurai, S. and T. Oyamada. 1995. Effects of the restriction of rooting zone with polyester sheet on the growth, yield and quality of tomato culture. Bull. Hort. Inst., Ibaraki Agric. Cent. 3: 23-29 (In Japanese with English abstract).

Sitton, B. G. 1949. The effects of different methods of girdling bearing and defruited tung branches. Proc. Amer. Soc. Hort. Sci. 53: 119-124.

Takahata, K. and H. Miura. 2014. Increasing the sugar concentration in tomato fruit juice by coiling wire around plant stems. HortTechnology 24: 76-80. 